\title{
Gastric Carcinoid Tumour as a Cause of Severe Upper Gastrointestinal Haemorrhage
}

A 39-year-old woman was admitted on an emergency basis with severe upper gastrointestinal bleeding. On examination, she was shocked and had a haemoglobin of $37 \mathrm{~g} / \mathrm{l}$. Following resuscitation, she underwent an emergency upper gastrointestinal endoscopy, which showed a polypoid lesion in the antrum of the stomach (Figure 1). As she remained unstable, a laparotomy was undertaken, at which the palpable lesion was identified (Figure 2) and excised using an elliptical incision, with clear macroscopic margins. Pathological examination of the gastric tissue revealed a gastric carcinoid tumour (Figure 3). The patient subsequently underwent a radical subtotal gastrectomy with Roux-en-Y gastrojejunal anastomosis. Histology showed that the resection margins were free from any tumour.

Four previous cases of severe bleeding from a gastric carcinoid, requiring surgical treatment, have been reported [1-4].

In all cases, a single gastric carcinoid of the sporadic type was found. In two of these cases, abnormal submucosal vasculature eventually opening up onto the mucosal surface was thought to explain the severity of the bleeding [1,2]. This also appears to have been the situation in the present case, with large feeding blood

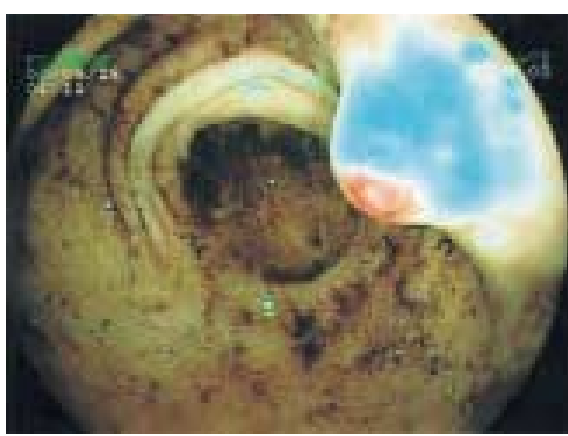

Figure 1 Endoscopic view of the polypoid lesion in the antrum of the stomach, with a prominent nonbleeding visible vessel at the tip. vessels to the tumour and an apparent nonbleeding visible vessel at endoscopy.

Three types of tumour have been classified. Type I and II tumours are characteristically multiple and small, with low malignant potential. Type III tumours are usually single and associated with a high malignant potential. More radical surgery, such as complete or partial gastrectomy, is required in such cases [5]. As this patient had a type III tumour, it was considered that an aggressive surgical approach was indicated, and she therefore subsequently underwent a radical subtotal gastrectomy.

We would suggest that if a lobulated tumour is found at endoscopy, gastric carcinoid tumour should be considered in the differential diagnosis. Although these tumours are rare, recognition is important, as certain types are associated with a high malignant potential.

\section{H. J. Dallal ${ }^{1}$, R. Ravindran ${ }^{2}$, P. M. King ${ }^{2}$, P. S. Phull 1 \\ ${ }^{1}$ Gastrointestinal Unit, Aberdeen Royal Infirmary, Aberdeen, United Kingdom \\ ${ }^{2}$ Dept. of Surgery, Aberdeen Royal Infirmary, Aberdeen, United Kingdom}

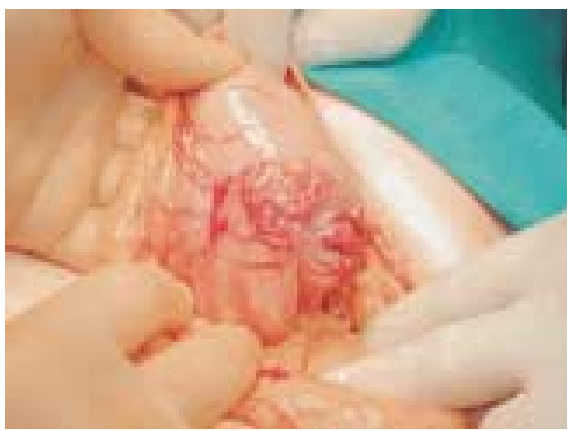

Figure 2 The posterior wall of stomach at laparotomy, showing a multilobed, irregular lesion $(3.6 \mathrm{~cm}$ in diameter), with large feeding vessels.

\section{References}

${ }^{1}$ Roncoroni L, Costi R, Canavase G et al. Carcinoid tumor associated with vascular malformation as a cause of massive gastric bleeding. Am J Gastroenterol 1997; 92: $2119-2120$

${ }^{2}$ Honig LJ, Weingarten G. A gastric carcinoid tumor with massive bleeding. Am J Gastroenterol 1974; 61: 40-46

${ }^{3}$ Purcell R, Singh I, Lewis E et al. Gastric carcinoid presenting with massive upper gastrointestinal bleeding. N Y State J Med 1988; 88: 80-81

${ }^{4}$ Teh $\mathrm{CH}$, Low $\mathrm{CH}$. Gastric carcinoid, a rare form of gastrointestinal carcinoid: a report on three cases. Hepatogastroenterology 1994; 41: 298-301

${ }^{5}$ Davies MG, O'Dowd G, McEntee GP et al. Primary gastric carcinoids: a view on management. Br J Surg 1990; 77: $1013-1014$

\section{Corresponding Author}

\section{H. J. Dallal, M.D.}

GI Unit, Aberdeen Royal Infirmary Foresterhill

Aberdeen AB25 2ZN

United Kingdom

Fax: + 44-1224-840711

E-mail: hjdallal@yahoo.com

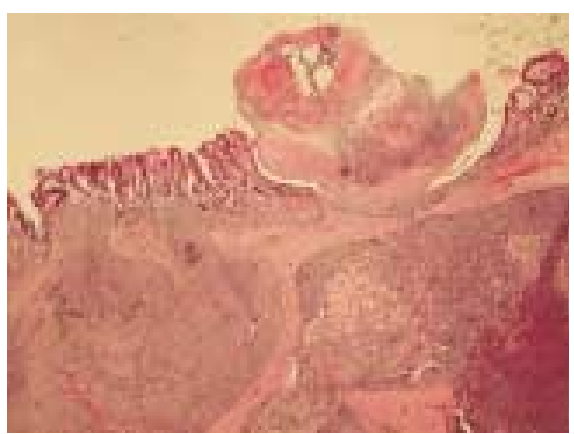

Figure 3 The lobulated tumour within the submucosa, consisting of bland cells with abundant cytoplasm (haematoxylin-eosin stain; original magnification $\times 20$ ). There was marked intravascular invasion, with the tumour extending to the resection margin. 